\title{
"O lustre do seu sangue" Bramanismo e tópicas de distinção no contexto português ${ }^{1}$
}

Ângela Barreto Xavier ${ }^{2}$

Este artigo visa analisar o modo como os discursos bramânicos que circulavam no espaço indiano (nos quais a pureza ritual e a endogamia eram topoi recorrentes) foram percebidos, experienciados e apropriados pelos agentes ao serviço da coroa de Portugal. Entre outros aspectos, interessa-me perceber em que medida é que esses discursos tiveram paralelo em (ou dialogaram com) os discursos linhagísticos que alimentaram os estatutos de limpeza de sangue, cada vez com maior expansão e aplicação no contexto metropolitano ibérico e seus respectivos territórios imperiais

Palavras-chave: Limpeza de sangue - nobreza - bramanismo

\section{"The honor of your blood"}

\section{Brahmanism and topics of distinction in the Portuguese context}

This article is aimed at analyzing how the Brahmanic speeches that filled the Indian space (in which ritual purity and endogamy were recurring topoi) were perceived, experienced and appropriated by the agents serving the Portuguese crown. Among other aspects, it interests me to understand to which extent such speeches found an equivalence (or established a dialogue) with the lineage-related speeches that nourished the blood purity rules in an increasingly expanded and frequent way in the Iberian metropolitan context and in their respective imperial territories.

Keywords: Blood purity - nobility - Brahmanism

\footnotetext{
${ }^{1}$ Artigo recebido e aprovado para publicação em julho de 2010.

${ }^{2}$ Professora do ICS - Universidade de Lisboa. E-mail: angela.xavier@ics.ul.pt
} 


\section{"L'honneur de son sang"}

\section{Brahmanisme et topiques de distinction dans le contexte portugais}

Cet article cherche à analyser la façon dont les discours brahmaniques qui circulaient dans l'espace indien (dans lesquels la pureté rituelle et l'endogamie étaient des topoï récurrents) ont été entendus, expérimentés et appropriés par les agents au service de la couronne du Portugal. Parmi d'autres aspects, je me suis employée à vérifier dans quelle mesure ces discours ont eu un parallèle (ou ont dialogué) avec les discours lignagiers qui ont alimenté de façon de plus en plus étendue et de plus en plus courante les status de pureté de sang dans le contexte métropolitain ibérique et dans ses territoires impériaux respectifs.

Mots-clés: Pureté du sang - noblesse - brahmanisme

Em 1516, quando registou no seu Livro muitas impressões sobre os modos de vida nos diferentes principados e entidades políticas da Índia que veio a conhecer, Duarte Barbosa disponibilizou informações importantes sobre as características das elites que compunham estes territórios, seus critérios de diferenciação, e aquilo que na época se designava por "ritos e costumes". De entre os vários territórios que o atraíram, foram as regiões do Guzerate e do Malabar as que ocuparam mais páginas do seu tratado. Por exemplo, Barbosa nota que no reino de Calecute a sucessão masculina fazia-se por via feminina, de modo a garantir a linhagem de sangue ("a verdadeira cepa jaz nas mulheres"), razão pela qual os elementos femininos da família real eram muito honrados e bem servidos. Barbosa explica o modo pelo qual os reis do Malabar procuravam controlar a geração dos seus sucessores. Aos doze anos de idade, a jovem donzela começava por ser entregue a um mancebo "de linhagem de fidalgos", e, mais tarde, "pera provesão de seu apetite, toma qual bramene". Os brâmanes são "antre eles sacerdotes como antre nós os crelgos", "todos de uma linage; não são feitos de outras gentes como nós, senão o que é filho de bramene será bramene". Mais adiante, explica que "casam à nossa maneira", mas que "não há-de casar salvo o irmão mais velho, e daquele se faz cabeça como morgado e os outros todos ficam solteiros, que não casam nunca", podendo estes, porém, dormir com outras mulheres, "porquanto são bramenes e nenhuma molher se lhes nega". Páginas antes, quando descrevera os brâmanes

${ }^{3}$ O Livro de Duarte Barbosa. Edição crítica e anotada por Maria Augusta de Veiga e Sousa, 2 vols., Lisboa IICT-CNCDP, 2000, vol. 2, pp. 115-118, pp. 157-163. Muitas dessas imagens aparecem na Relação do Piloto Anónimo, na Navegação às Índias Orientais de Tomé Lopes (v. Luís de Albuquerque et. al., O Confronto do Olhar. O Encontro dos povos na época das navegações. Lisboa: Cami- 
do Guzerate, Barbosa enunciara já alguns dos aspectos que registaria no Malabar (nomeadamente a ideia de os brâmanes serem originariamente sacerdotes, e da sua identidade ser linhagística), acrescentando mais pormenores sobre os seus costumes religiosos: "fazem a sua oração a Deos, e dizem que confessam ser um deos verdadero, criador de todas as cousas, e que são três em huma soo pessoa", ou "teem por serimonia o lavar e dizem que per ali se salvam."

Poucos anos antes, Afonso de Albuquerque convencera o rei D. Manuel a estimular o casamento entre soldados portugueses e mulheres indianas, dando assim origem ao que ficaria doravante conhecido como o grupo dos casados. $\mathrm{O}$ 'projecto' de Albuquerque era inspirado, segundo se pode intuir da descrição deste episódio feita por João de Barros na sua Ásia, numa prática que fora desenvolvida pelos romanos, quando da conquista do Lácio. De modo a se estabelecerem, a se enraizarem, e a serem capazes de conservar essa conquista, os romanos tinham-se unido às filhas dos sabinos e feito amizade com os seus príncipes, episódio imortalizado por Tito Lívio e por Plutarco, e com grande impacto na literatura e na arte dos séculos XVI em diante. ${ }^{5}$

Ao contrário da recepção positiva que o rapto das sabinas teve na imaginação europeia, e talvez com alguma surpresa para o seu promotor, sabemos pelas cartas de Afonso de Albuquerque, pelos Comentários redigidos pelo seu filho, e por outros testemunhos coetâneos e posteriores parte deles inventariados por Diogo Ramada Curto no clássico estudo "Representações de Goa: Descrições e Relatos de Viagem"6 -, que os casamentos entre os conquistadores portugueses e as indianas conquistadas foram, desde o início, controversos. Em primeiro lugar, não foi grande o entusiasmo das elites indianas face a estas proposições matrimoniais. Para estas, o casamento com portugueses de origem social relativamente baixa (porque eram estes, na sua maioria, os que estavam disponíveis para casar) desacreditava "o lustre do seu sangue", e não comportava contrapartidas aliciantes. Também a

nho, 1991, pp. 155-166. Mais atento às riquezas naturais do que às gentes, a Summa Oriental de Tomé Pires constitui, para as primeiras décadas da presença portuguesa, uma descrição igualmente incontornável (v. A Suma Oriental de Tomé Pires e o Livro de Francisco Rodrigues, leitura e notas de Armando Cortesão, Coimbra, Imprensa da Universidade, 1978).

${ }^{4}$ O Livro de Duarte Barbosa. op. cit., vol. 1, pp.183-187.

${ }^{5}$ João de Barros, Ásia, 2a Década, L. 5, cap. 2; $4^{a}$ Década, L. 7, cap. 11; L. 8, cap. 15.

${ }^{6}$ Diogo Ramada Curto, “Representações de Goa: Descrições e Relatos de Viagem”, In: Rosa Maria Perez e Joaquim Pais de Brito (orgs.), Histórias de Goa. Lisboa, Museu de Etnologia - CNCDP, 1997. 
fidalguia portuguesa se mostrou reticente face a este tipo de estratégia, recusando, na maior parte dos casos, unir-se pelo matrimónio às mulheres indianas, ainda que alvas e de boa feição, por considerar que isso contaminaria a sua geração.

Eventos paradigmáticos e paralelos no tempo, e porque ambos remetem para discussões e controvérsias que estavam a ter lugar sobre dispositivos de identificação, distinção e exclusão, nessa época, no reino de Portugal, o Livro de Duarte Barbosa e os casamentos promovidos por Afonso de Albuquerque constituem um bom ponto de partida para esta reflexão sobre as articulações entre bramanismo e tópicas de distinção no contexto português.

Noutros lugares discuti a recepção que as uniões promovidas por Albuquerque tiveram no contexto do Estado da Índia e no mundo metropolitano, e o malestar daí resultante, em franco contraponto com a imagem idílica de uma sociedade luso-indiana, ícone luso-tropicalista. ${ }^{7} \mathrm{Na}$ sequência desses trabalhos, nos quais mostrei a inconveniência destes casamentos para as elites indianas que se reivindicavam de origem kshatrya e bramânica, interessa-me focalizar, agora, no modo como os modelos de distinção associados a essas elites, e, em concreto, a percepção do regime de distinção que operava entre os brâmanes, foram apreendidos em contexto português, no âmbito dos encontros e desencontros imperiais, intersectando práticas e discursos.

Assim sendo, pretendo identificar, em primeiro lugar, conexões entre imaginações do império que circulavam no contexto português e as que eram produzidas e/ou existiam nas culturas políticas das sociedades ditas "colonizadas". Trata-se de um recorte directamente implicado com a circulação de discursos em contexto transnacional, e o modo como estes se foram moldando mutuamente. Este enfoque é estreitamente inspirado pela historiografia que tem pensado paralelamente, para

\footnotetext{
7 "Dissolver a Diferença. Conversão e Mestiçagem no Império Português”, In: Cabral, Wall et al., Itinerários. Lisboa, Imprensa de Ciências Sociais, 2008. pp. 709-727; “Nobres per geração' Os descendentes dos portugueses na Goa seiscentista”, Ângela Barreto Xavier e Catarina Madeira Santos, Cultura Intelectual das Elites Coloniais, número temático da revista Cultura - História e Teoria das Ideias, $2^{\text {a }}$ série, vol. XXV; "David contra Golias na Goa seiscentista e setecentista. Escrita identitária e colonização interna”, Ler História, n 49, 2005.

${ }^{8} \mathrm{O}$ conceito imaginação aqui evocado vincula-se aos sentidos que lhe são atribuídos por Ronald Inden em Imagining India (C. Hurst \& Co. Publishers, 1990), mas também por Benedict Anderson, em Imagined Communities: reflections on the origins and spread of nationalism (Verso, 1991).
} 
a época moderna, os processos históricos ocorridos nas "quatro partes do mundo" (e muitos dos livros publicados nos últimos anos por Sanjay Subrahmanyam e por Serge Gruzinski são muito inspiradores). Por exemplo, tanto nas Explorations in Connected Histories (2005) como antes em Textures of Time (2003), entre outros, Subrahmanayam demonstrou a existência de vários processos culturais que ocorreram paralelamente (embora nem sempre com as mesmas características) no mundo europeu e asiático, disponibilizando um corpo de informação sobre as sociedades indianas da época moderna que permite (e obriga a) rever a história das relações culturais e intelectuais (e políticas) entre portugueses e indianos. ${ }^{9}$

De que forma é que os discursos bramânicos que circulavam no espaço indiano (nos quais a pureza ritual e a endogamia eram topoi recorrentes) foram percebidos, experienciados e apropriados pelos agentes ao serviço da coroa de Portugal? Qual foi a relação estabelecida entre essas 'coisas' (i.e., esses processos históricos locais), essas 'palavras' (i.e., os discursos produzidos pelos agentes imperiais portugueses in loco, a partir da metrópole, ou de outras colónias) e outros discursos de distinção que circulavam no espaço ibérico? Em que medida é que esses discursos tiveram paralelo em (ou dialogaram com) os discursos linhagísticos que alimentaram os estatutos de limpeza de sangue, cada vez com maior expansão e aplicação no contexto metropolitano ibérico e seus respectivos territórios imperiais? ${ }^{10} \mathrm{Ou}$, e esticando ainda mais esta hipótese de trabalho, podemos ainda perguntar em que medida é que o bramanismo enquanto, discurso, se constituiu como mais um template inspirador dos discursos que sustentavam a defesa da limpeza de sangue - e de determinada concepção de nobreza - no mundo ibérico? ${ }^{11}$

\footnotetext{
${ }^{9}$ Sanjay Subrahmanyam, Explorations in Connected History: From the Tagus to the Ganges, USA, OUP, 2005; Explorations in Connected History: Mughals and Franks, India, OUP, 2005; Velcheru Narayana Rao, David Shulman, Sanjay Subrahmanyam, Textures of Time: Writing History in South India 1600-1800, Other Press, 2003.

${ }^{10}$ Os estudos que Diogo Ramada Curto dedicou às representações sobre a Índia, produção escrita, e práticas de identidade em contexto imperial - e remeto para a leitura dos estudos publicados na História da Expansão Portuguesa, no livro Histórias de Goa, e nos mais recentes Cultura Escrita (Lisboa, Imprensa de Ciências Sociais, 2007) e Cultura Imperial e Projectos Coloniais (São Paulo, UNICAMP, 2009), os quais reconfiguraram as formas de abordagem desses problemas, são referências importantes para este trabalho.

${ }^{11}$ Estas perguntas remetem para os objectivos que orientam o projecto "Mimetismo colonial no império português", coordenado por Ricardo Roque, e do qual faço parte, no contexto do qual se procuram analisar processos de mimesis no contexto do colonialismo português, tresvazando, porém, os significados tradicionalmente atribuídos aos processos de going native. Assim sendo, em vez de acentuar, apenas, a dimensão ambivalente que o mimetismo colonial adquiriu, como foi
} 


\section{Tópicas bramânicas}

Dado o carácter introdutório deste estudo, este leque de questões e as escalas para as quais remetem serão aqui discutidos de forma simultaneamente vaga e restrita. Na realidade, de momento limitar-me-ei a explorar uma selecção impressionista de representações do bramanismo, produzidas nos séculos XVI e XVII, articulando-os com topoi presentes nos discursos sobre a nobreza, a linhagem e a pureza do sangue, produzidos na mesma altura.

Para discutir parte destas questões no contexto imperial português dispomos, já, de alguns importantes estudos. Desde logo, os trabalhos que, nas décadas de 1980 e 1990 elegeram as representações (sobretudo as representações incorporadas nos relatos de viagem) como objecto de estudo. ${ }^{12}$ Depois, os estudos de Ines Županov, centrados, sobretudo, no universo de produção jesuíta, e

identificado no clássico ensaio "On mimicry and man. The ambivalence of colonial discourse" de Homi Bhaba (The location of culture, Routledge, 1994) em que a realidade ocidental surge como o template original que o 'colonizado' devia imitar (ou podia, eventualmente, parodiar), procuram-se identificar zonas de contacto que podem ter sido produtoras, de uma outra forma, da própria situação colonial e da sua durabilidade, zonas nas quais a apropriação de ideias 'indígenas', de tecnologias, de práticas, é agora entendida como modalidade dinâmica, produtora e reprodutora da interacção colonial. Sob alguns ângulos, a proposta de Michael Taussig, em Mimesis and Alterity: A Particular History of the Senses (1993), segundo a qual há lugares coloniais nos quais é difícil dizer quem é o imitador e quem é o imitado, é inspiradora dessa vontade de identificar situações de encontro colonial que potenciaram o recurso a múltiplas e inesperadas formas de imitação colonial.

${ }^{12}$ Trabalhos clássicos nesta área são os de Luís Filipe Barreto, Descobrimentos e Renascimento. Formas de Ser e Pensar nos séculos XVI e XVII, Lisboa, INCM, 1983; Luís Graça, A visão do Oriente na literatura portuguesa de viagens: os viajantes portugueses e os itinerários terrestres, 1560-1670, Lisboa, INCM, 1983; Ma Augusta Lima Cruz, "La Vision de l'Indien chez les premiers chtoniqueurs portugais de l'Asie: la fixation d'une image", La Decouverte, le Portugal et l'Europe, Actes du Colloque. Paris, FCG, 1990, p. 235-241; W.G.L. Randles, “Peuples Sauvages' et 'États despotiques': la pertinence, au XVIe siècle de la grille aristotélicienne pour classer les nouvelles societés révélées par les Découvertes au Brésil, en Afrique et en Asie", Mare Liberum: Revista de História dos Mares, no 3, Dez. 1991, p. 229-307; Luís de Albuquerque, António Luís Ferronha, José da Silva Horta, Rui Loureiro, O confronto do olhar. O encontro dos povos na época das navegações portuguesas. Séculos XV e XVI, Lisboa, Ed. Caminho, 1991; Sanjay Subrahmanyam, "O gentio indiano visto pelos portugueses no século XVI”, Oceanos, n 19/20, Setembro 1994; Idem, "O romântico, o oriental e o exótico: notas sobre os portugueses em Goa”, in: Rosa Maria Perez e outros (coord.), Histórias de Goa. Lisboa, Museu Nacional de Etnologia, 1997, pp. 29-43; Diogo Ramada Curto, "Representações de Goa: Descrições e relatos de viagem, in: Rosa Maria Perez e outros, coord., Histórias de Goa. Lisboa. Museu Nacional de Etnologia, 1997, p. 45-85. Ver, ainda, a boa sintese europeia providenciada por Joan-Pau Rubiès, Travel and Ethnology in the Renaissance. South India through European Eyes, 1250-1650, Cambridge, CUP, 2005. 
na importância desta produção quer em termos identitários, quer em termos de conhecimento relevante para entender a Índia deste período. Nestes estudos, o jogo de proximidades e distâncias entre 'europeus' e 'indianos brâmanes' foi bem explorado, muito embora essa discussão não tenha incluído os impactos políticos e sociais concretos que tais discursos e debates podem ter produzido nos grupos sociais aos quais se estavam a referir, para além dos seus impactos sobre os seus próprios produtores. ${ }^{13}$

Esta literatura permite definir alguns dos contornos deste puzzle: dispomos de um bom inventário (se bem que não exaustivo) das fontes produzidas em contexto imperial português nas quais brâmanes e bramanismo se tornaram objecto de análise directa ou indirecta, de discussões em torno aos diálogos, encontros, e desencontros entre brâmanes e jesuítas, e de alguns estudos sobre a agency dos brâmanes convertidos em contexto imperial português.

Dito isto, podemos então regressar à escrita de Duarte Barbosa.

Como é sabido, sobre Duarte Barbosa a informação é parcimoniosa. Segundo Gaspar Correia, Barbosa era sobrinho de um antigo feitor de Cananor, Gil Fernandes Barbosa, com quem aprendera a língua malabar, razão pela qual fora escolhido por Afonso de Albuquerque para ocupar a função de intérprete. Em 1511, encontra-se em Cananor, como escrivão daquela feitoria, ocupando a mesma função em Calecute, juntamente com Gaspar Correia. Depois de uma viagem ao Mar Vermelho, na qual acompanhara Lopo Soares de Albergaria, regressa como primeiro escrivão, residindo naquela cidade até ao fim da sua vida, por volta de 1546 ou 1547. Durante a sua estada em Cananor, terá certamente travado conhecimento com Fernão de Sá Soutomaior, capitão na fortaleza portuguesa estabelecida naquela cidade, cerca de 1534, e com Diogo de Sá, seu filho, que, mais tarde, redigiria vários tratados, entre os quais o importante Inquisição e Segredos da Fé e o Tratado dos Estados Eclesiásticos e Seculares. ${ }^{14}$

No Livro das cousas, redigido por volta de 1516, Barbosa descreve a geografia humana e física dos lugares onde os portugueses se tinham estabelecido ou onde tinham interesses políticos e económicos, bem como os usos e os costumes

\footnotetext{
${ }^{13}$ Máxime Ines Županov, Disputed Mission: Jesuit Experiments and Brahmanical Knowledge in Seventeenth-Century Indi, Deli, OUP, 2000; ver a esse propósito, Ângela Barreto Xavier, "David contra Golias..., op. cit.

${ }^{14}$ Sobre Diogo de Sá, ver Ana Cristina da Costa Gomes e Diogo de Sá, Os Horizontes de um Humanista. Lisboa, Prefácio, 2004, passim, e bibliografia aí referida.
} 
daqueles que reconhecia como diferentes. Como outros escritores do seu tempo, insiste na verdade da sua relação, e no método de conhecimento por ele utilizado (a conversação com a população local, a experiência, a observação), trabalhando retoricamente a sua informação de modo a tornar a diferença compreensível ao leitor português. Este jogo entre o familiar e o diferente caracterizou, de facto, os primeiros momentos do encontro de Barbosa com a Ásia, tornando o seu livro muito rico em informação. ${ }^{15}$

Um dos primeiros portugueses a registar aspectos característicos do grupo bramânico, de entre as semelhanças que Barbosa encontra entre os brâmanes, gostaria de destacar a questão da linhagem. "O que é filho de bramene será bramene" e "não são feitos de outras gentes como nós" ${ }^{6}$ são dois enunciados nos quais Barbosa parece diferenciar o regime de identidade e distinção dos brâmanes do universo social que era o seu. Ou seja, no início do século XVI - e ao contrário do que alguma literatura mais recente tem desenvolvido sobre a construção britânica da identidade bramânica ${ }^{17}$ - era claro para os portugueses que contactavam com estes grupos que o reconhecimento da identidade de brâmane passava necessariamente pelo critério linhagístico. Mas Barbosa também se refere com curiosidade à obsessão pela limpeza - "têm por grande cerimónia o lavar. Dizem que, por ali, se salvam" - a qual, na época, também devia diferenciar as práticas destes grupos das da maior parte dos portugueses que aí se estabeleciam. É evidente que Barbosa representava um português do tipo médio, não podendo as suas palavras - e o seu espanto - serem tomados como representativos de toda a comunidade de portugueses. O carácter local do seu registo não lhe retira, porém, relevância, até porque muitos dos tópicos que aí foram narrativizados reaparecem em vários lugares da literatura de viagens, da correspondência, das histórias e crónicas, e de outra tratadística sobre a Índia, suas gentes e seus costumes, tanto de origem portuguesa, quanto de autoria europeia.

\footnotetext{
${ }^{15}$ Infelizmente não se conhece o manuscrito original do tratado de Duarte Barbosa, mas sim várias cópias manuscritas - e impressas - em línguas diferentes, tendo sido uma delas a base da primeira versão impressa, incluída na compilação Della Navigationi e Viaggi de Ramusio.

${ }^{16}$ O Livro de Duarte Barbosa. Edição crítica e anotada por Maria Augusta de Veiga e Sousa, 2 vols., Lisboa IICT-CNCDP, 2000, vol. 2, pp. 115-118.

${ }^{17}$ Pamela Price, "Ideology and Ethnicity under British Imperial Rule: Brahmans, Lawyers and KinCaste Rules in Madras Presidency", Modern Asian Studies, vol. 23, n 1, 1989, pp. 151-177.
} 
Escrevendo a partir da metrópole, João de Barros acrescenta novos conteúdos às descrições deixadas por Barbosa. Em vários lugares da Ásia aparecem brâmanes desempenhando diversos papéis políticos, desde conselheiros, embaixadores e intermediários de reis, até mesmo reis. Logo quando Vasco da Gama se encontra com o Samorim de Calecute, por exemplo, ao lado dele estava "um homem de grande idade, que era o seu brâmane maior, vestindo as vestiduras brancas, representando nelas e em sua idade e continência ser homem religioso", o qual iria ajudar o rei durante a reunião. ${ }^{18}$ Dois anos mais tarde, Pedro Álvares Cabral recorreria a um brâmane, "qual era de uns que tomam por religião andarem em penitência per todo o Mundo, nus, com as cadeas de redor de si, cheos de bosta de vacas por mais desprezo de suas pessoas, e geralmente os que tomam esta vida, se são do género gentio, chamando-lhe jogues", para contactar o rei de Cochim. ${ }^{19}$ E no Ceilão, Lopo Soares de Albergaria teria oportunidade de verificar que tal como no Malabar, também aí os reis eram brâmanes, "porque acerca do gentio daquelas partes, estas duas cousas andam juntas - o sacerdócio e o governo dos homens". Nessa espécie de teocracia, "os reis tenham grande acatamento aos seus sacerdotes, e muito maior às cabeças deles, as quais tem aquela jurdição que acerca da clerezia entre nós tem os bispos, os mesmos reis são brâmanes, e são superiores de todos em seu reino". João de Barros manifestou estranheza perante esta associação na pessoa do rei do governo secular e do senhorio "das almas e autores interiores do ânimo", ${ }^{20}$ o que não deixa de ser surpreendente, já que o período em que Barros viveu tem vindo a ser caracterizado por muitos historiadores, entre os quais me incluo, como uma época em que a aliança entre poder político e poder religioso, e essa vontade de senhorio das almas por parte da coroa se tornava cada vez mais explícita. ${ }^{21}$

A par destas características, a resistência do brâmane em "se tocar com gente fora de seu sangue", 22 o que levara o samorim de Calecute, por exemplo, a recusar entregar uns brâmanes como reféns a Pedro Álvares Cabral, já que, "por razão

\footnotetext{
${ }^{18}$ João de Barros, Ásia, $1^{a}$ Década, L. IV, cap. VIII.

${ }^{19}$ Idem, L. V, cap. 4, cap. 15.

${ }^{20}$ Idem, $3^{a}$ Década, L. II, cap. 2.

${ }^{21}$ Ver por ex., José Pedro Paiva, Os Bispos no Reino e no Império, Coimbra, Almedina, 2006; Federico Palomo, Fazer dos Campos Escolas Excelentes, Lisboa, FCG, 2003

${ }^{22}$ Ines Županov, Disputed Mission: Jesuit Experiments and Brahmanical Knowledge in SeventeenthCentury India, Deli, OUP, 2000, máxime.
} 
de sua religião, não podiam comer nem dormir senão em sua própria casa, e, quando se tocavam com gente fora de sua geração, tinham suas purificações e cerimónias", era recorrentemente sublinhada. Segundo Barros, parte dos costumes e/ou ritos desses brâmanes eram marcados, de facto, pela sua obsessão com os lavatórios. ${ }^{23}$ Essa associação entre proibição de contacto privado com pessoas de fora do seu grupo e a execução de rituais de limpeza aparece noutras narrativas quinhentistas laicas e em variados lugares da escrita como sendo constitutivos da "identidade bramânica". ${ }^{24}$

Enfim, na primeira metade do século XVI, os temas da hereditariedade da identidade, da distinção assente sobre a pureza do sangue, e sobretudo do corpo, e da associação entre brâmanes e poder político, são recorrentes quando, na literatura de viagens, na cronística, e noutros lugares, os brâmanes se tornavam objectos de discurso. A partir de finais do século XVI, altera-se o modelo de apropriação discursiva deste grupo social e suas práticas. De objectos de discurso que povoavam narrativas mais alargadas, os brâmanes e as suas práticas tornaram-se, eles próprios, nos protagonistas de um outro tipo de textos.

É sabido que com a entrada dos religiosos no registo das experiências tidas localmente (e há testemunhos desse tipo de registo desde o início do século XVI, aí se destacando os relatórios enviados pelo bispo de Dume ao rei D. Manuel, pelo padre Miguel Vaz a D. João III, e por outros missionários) o volume de informação sobre as práticas religiosas e sociais dos indianos aumenta exponencialmente, explodindo com a chegada da Companhia de Jesus àqueles territórios.

Nesse contexto, e porque identificados com o sacerdócio local, os brâmanes tornaram-se nos principais interlocutores (e rivais) dos eclesiásticos cristãos, o mesmo acontecendo com o seu universo religioso e as suas práticas sociais, os quais se converteram num importante objecto do discurso cristão. As percepções das práticas religiosas locais foram formatadas e decifradas, num primeiro momento, em função daquilo que era considerado definidor da religião (livros, sacerdotes,

\footnotetext{
${ }^{23}$ João de Barros, Ásia, $1^{a}$ Década, L. VI, cap. 7; L. VII, cap. 6; 2a Década, L. II, cap. 8 . A par destas descrições, os brâmanes de diversas partes da Índia são sujeitos a muitas outras referências, na maior parte altamente depreciativas, sendo as mais fortes de entre estas a ideia de que tinham uma forte inclinação para a falsidade, topos que atravessou toda a presença portuguesa na Índia e os discursos sobre estes grupos, mas para aquilo que nos interessa aqui analisar, esta tópica explicitamente negativa não é particularmente relevante.
}

${ }^{24}$ João de Barros, op. cit., L. IV, cap. 7; L. V, cap. 4; L. VI, cap. 15. 
templos, rituais), mas o seu registo fez-se, também, em função dos templates (nem sempre coincidentes, aliás) disponibilizados pelos próprios brâmanes.

Considerem-se, a esse propósito, as reflexões deixadas pelo jesuíta Gonçalo Fernandes Trancoso, em 1616, sobre a religião dos brâmanes, publicadas por Josep Wicki em 1973 sob o título Tratado do Padre Gonçalo Fernandes Trancoso sobre o Hinduísmo Maduré $1616 .^{25}$ Propostas contemporâneas de Trancoso são as de Jacopo Fenício (1558-1632), jesuíta que esteve na corte de Calecute nos primeiros anos do século XVII, autor do Livro da Seita dos Índios Orientais, de João Delgado Figueira, inquisidor de Goa e autor do parecer sobre "a duvida de certos synaes gentílicos”, de 1619, de frei Francisco Negrão, franciscano que teria escrito algo de semelhante na sua perdida crónica franciscana, do padre Francisco Garcia, compilador de O Homem das trinta e duas perfeições, e, evidentemente, a Informatio de quibusdam moribus nationis Indicae, de Roberto di Nobili, entre as várias cartas e textos que produziu no contexto da controvérsia que o opôs a Trancoso. Posterior era o tratado escrito por frei Manuel Barradas, c. 1634, e enviado a Manuel Severim de Faria, intitulado Da seita dos Índios orientais e principalmente dos Malabares, o qual se trata, na sua maior parte, de uma glosa de Fenício. ${ }^{26}$

A controvérsia sobre a qual assentou a escrita do tratado de Trancoso - em torno aos atributos religiosos e sociais das práticas rituais dos indianos - foi magnificamente trabalhada por Ines Županov no livro Disputed Mission..$^{27} \mathrm{O}$ que aqui se persegue, ao analisar Trancoso, é ligeiramente diferente daquilo que interessou esta autora, pelo que não vou aqui repetir o que aí foi analisado. O que agora se pretende é identificar os contornos da tópica bramânica de Trancoso, com o objectivo de perceber de que forma é que esta participou da communis opinio portuguesa, seiscentista, sobre as articulações entre identidade e hereditariedade, contribuindo dessa forma para forjar e/ou reforçar certos modelos de distinção.

O livro de Gonçalo Fernandes Trancoso é apresentado por Josep Wicki como se desdobrando em duas partes, uma primeira na qual o seu autor se concentra em analisar os costumes e cerimónias, os quais considera parte de um "modo de proceder" mais geral que incluía as "siensias e lleis", e uma segunda parte

\footnotetext{
${ }^{25}$ Tratado do Pe. Gonçalo Fernandes Trancoso sobre o Hinduísmo (Maduré 1616), ed. de Josep Wicki, Lisboa, Centro de Estudos Históricos Ultramarinos, 1973.

${ }^{26}$ Para se ter uma visão mais completa do que se produziu, nessa época, sobre a religião e os costumes dos indianos, veja-se o elenco de fontes referenciado por Ines Županov em Disputed Mission...

${ }^{27}$ Ines Županov, Disputed Mission, op. cit.
} 
constituída por um conjunto de textos onde eram elencadas as punições que os brâmanes deviam sofrer sempre que violavam as normas rituais estabelecidas. Ou seja, o "Sumario das serimonias e modo de proceder dos brâmanes destas partes da India conforme as suas lleis e doutrinas dos seus doutores" - a afirmação da identidade "era seguido por um "compendio de ditos de graves autores aserqua dos brâmanes que vam contra suas seitas e custumes com as penitensias que devem fazer (...)" - o controlo dessa mesma identidade. Não será esta organização textual, em si-mesma, sintomática de um modelo que operava no espaço europeu da época?

Para Trancoso, para se ser brâmane era necessário "que seja bem nacido", mas também que se submetesse a determinados rituais que permitiam que essa identidade de partida tivesse efeito. Por exemplo, caso o brâmane casasse e se tornasse um grihashta, devia casar "com molher bramana e bem nascida", e continuar a realizar as cerimónias legitimadoras da sua identidade de brâmane. ${ }^{28}$ Para que os filhos desse casal se tornassem brâmanes, deviam ser sujeitos a determinados rituais purificadores enquanto ainda estavam no ventre da mãe. No próprio dia do nascimento, o bebé brâmane era sujeito a várias cerimónias, entre as quais aquelas que tinham como fim purificá-lo "do vente emmundo" ou de "alguma culpa contra Brama”. ${ }^{29} \mathrm{O}$ puja às nove estrelas e a atribuição de nome à criança, dez dias depois do nascimento da criança, também era precedido de lavatórios do bebé e da mãe. Anos mais tarde, e de igual modo, seriam lavadas e purificadas as linhas que iriam ser impostas ao jovem brâmane, num dos principais rituais de identificação bramânica, aquele que o transformava num bramacharyia, i.e., no jovem brâmane. ${ }^{30}$

Depois de ter experimentado o estado de bramacharyia, o brâmane que se predispunha para o casamento, ou seja, que se iria tornar grihashta, devia submeter-se a mais um extenso conjunto de rituais que duravam quatro dias, entre os quais se destacavam os ritos de purificação e os ritos de fertilidade. Alguns desses ritos e das expressões "traduzidas" pelo jesuíta terão evocado universos que lhe eram familiares. Terá sido o caso do rito (e do mantra a ele associado), que dava início, no primeiro dia, ao casamento propriamente dito, e que se seguia a uma série ritual na qual os protagonistas eram o cônjuge e o seu sogro. "Vinde

\footnotetext{
${ }^{28}$ Tratado do Pe. Gonçalo, pp. 6 e 7.

${ }^{29} \mathrm{Idem}, \mathrm{pp} .12$ e 13.

${ }^{30}$ Idem, pp. 18-19, pp. 33-63.
} 
quá, donsella (...) vós nasestes de boa família, por eu casar convosco" era o vocativo deste mantra, no qual se reiterava, mais uma vez, o bom nascimento. Mas igualmente análogos terão sido os momentos em que se confirmava perante os parentes a probidade dos noivos, a troca de objectos que confirmavam a pertença mútua dos cônjuges, ou os ritos pelos quais se pedia "vida e pureza". ${ }^{31}$ Essa pureza continuava, ao longo da vida, desde que ritualmente preservada pelas cerimónias que marcavam o quotidiano destes brâmanes imaginados pelos jesuítas e por outros religiosos portugueses a partir da conjugação de várias prescrições textuais oriundas de "autores" diversos com as suas próprias experiências com brâmanes locais. No capítulo dedicado aos lavatórios rituais (dois por dia, e os que deviam ser feitos em dias especiais), Trancoso explica: "Se quereis saber o fruito de se lavar, hé que dá limpesa ao corpo e ao intendimento, e os peccados que se cometerem de noite em sonhos e por pensamentos ruins bota fora." ${ }^{32}$

À preservação do estatuto de brâmane correspondia o reconhecimento social da sua supremacia, suscitando axiomas como "somente o que hé brâmane está sempre purificado e nenhuma das outras castas o está". ${ }^{33}$

No "compendio de ditos de graves autores", Trancoso elenca as "penitensias" que os brâmanes faltosos deviam fazer para regressarem à comunidade bramânica, segundo vários textos, de proveniência distinta, mas que circulavam no Malabar seiscentista, servindo de referencial para os sacerdotes que presidiam aos tribunais de casta.

Para além de questões da vida concreta, em relação às quais os brâmanes se deviam comportar de determinada maneira, os temas da imundície e da pureza voltam a estar presentes nestes textos. A imundície, entendida como poluição, encontrava-se em momentos concretos da vida de cada brâmane (da vida mensal das mulheres, nomeadamente), implicando, por conseguinte, determinados comportamentos por parte de quem os vivia, tais como a total abstinência do contacto. Mas ela também resultava de comportamentos activos, tais como o contacto inesperado (ou desejado) como membros de castas consideradas mais baixas, quer na comensalidade, quer em situações de maior intimidade (ex. "todo

\footnotetext{
${ }^{31}$ Idem, pp. 72-91.

${ }^{32}$ Idem, p. 100.

${ }^{33}$ Idem, p. 245.
} 
o bramane que tocar carnalmente a parechi que hé molher da mais baixa casta, se não fizer o sandaraiana virudam não se irá o tal pecado"). ${ }^{34}$

Ines Županov mostrou-nos bem que o objectivo de Trancoso, ao compilar estas reflexões, era provar que os ritos realizados pelos brâmanes tinham uma dimensão religiosa, razão pela qual deviam ser abandonados depois da conversão - ao contrário do que era defendido por Roberto di Nobili e outros defensores da accomodatio, para quem havia uma separação entre a esfera religiosa e a esfera social, o que permitia, precisamente, a manutenção destas práticas depois da conversão, sem com isso lesar a nova identidade cristã. Ou seja, as referências à hereditariedade da identidade bramânica e aos rituais de purificação surgem neste contexto, devendo ser entendidas como parte desse processo argumentativo. É essa identidade argumentativa do texto que o torna, contudo, tão interessante, já que, seguindo os preceitos retóricos da época, Trancoso preocupou-se em elencar o maior número de exemplos possíveis (podendo ter incorrido, é certo, em deslizes de tradução, ou falseado alguma informação), deixando-nos, por isso mesmo, uma antologia da tópica bramânica que circulava no mundo social do Malabar do seu tempo. ${ }^{35}$

Se os manuscritos deixados por Gonçalo Fernandes Trancoso, Roberto di Nobili, pelo padre Manuel Barradas ou por Jacopo Fenício instituíram os ritos e costumes dos indianos (e sobretudo dos brâmanes) como objecto autónomo de discurso, providenciando cortes em profundidade sobre os mesmos, ${ }^{36} \mathrm{e}$ inventando discursivamente os brâmanes e o bramanismo, uma dinâmica distinta, tipicamente orientalista, preside à redacção da Ásia Portuguesa por Manuel Faria de Sousa, síntese de meados do século XVII, inspirada em João de Barros. ${ }^{37}$

\footnotetext{
${ }^{34}$ Idem, pp. 236 e ss., p. 252.

${ }^{35}$ Ver, a esse propósito, Velcheru Narayana Rao, David Shulman, Sanjay Subrahmanyam, Textures of Time: Writing History in South India 1600-1800, Other Press, 2003.

${ }^{36}$ Para além dos já citados estudos de Ines Županov, ver, ainda, "One civilty, multiple religions: Jesuit mission among St. Thomas Christians in India (16th-17th centuries)", JEMH, 9, 3-4, 2005, pp. 284-325; e também Joan-Pau Rubiès (2006), "Theology, ethnography, and the historicization of idolatry", Journal of the history of ideas, 67 (4). pp. 571-596; (2001) "The Jesuit discovery of Hinduism: Antonio Rubino's account of the history and religion of Vijayanagara (1608)", Archiv für religionsgeschichte, 3 (1), pp. 210-256; David N. Lorenzen, Who invented Hinduism: essays on religion in History, Yoda Press, 2006; "Gentile Religion in South India, China, and Tibet: Studies by Three Jesuit Missionaries", Comparative Studies of South Asia, Africa and the Middle East, 27.1, 2007, pp. 203-213.

${ }^{37}$ Manuel de Faria e Sousa, Ásia Portuguesa, Porto, Livraria Civilização, 1945, vol. I.
} 
É na quarta parte do $2^{\circ}$ tomo da Ásia Portuguesa que Manuel de Faria e Sousa aborda o tema dos "Deuses, ritos e cerimónias de nações asiáticas e, em particular, dos índios e dos malabares", retirado de uma "traduccion de lo que los Indios malabares tienen en opinion que nosotros la Biblia Sacra”, que segundo suas palavras, se encontrava no elenco de manuscritos que utilizou, ${ }^{38}$ o qual lhe tinha sido transmitido pelo seu contemporâneo Manuel Severim de Faria (1584-1655), de quem Sousa é, claramente, tributário.

O aparelho de Faria e Sousa assenta sobre a ideia de que "as analogias encontram-se na substância, por mais que divirjam nos acidentes", o que lhe permite utilizar o exemplo dos malabares para "servir de informação do culto religioso de todas e das suas políticas”, mas também para estabelecer uma história comparada das várias religiões do mundo, as quais coloca no mesmo plano discursivo, quer remetendo para formas religiosas da Grécia antiga, quer para o Cristianismo que ele próprio conhecia. Aliás, é este modus operandi, esta capacidade de estabelecer analogias constantes entre situações distintas, típica entre os eruditos da época, que justifica a hipótese com que iniciei esta reflexão: que os discursos produzidos em torno ao bramanismo podem ter constituído um repositório de argumentos utilizáveis noutros lugares e noutras situações, estando prontos a ser mimetizados.

Ao contrário de Gonçalo Fernandes Trancoso, explicitamente concentrado nos ritos e costumes dos brâmanes, os capítulos que Manuel de Faria e Sousa dedica às práticas religiosas dos indianos são mais panorâmicos, obedecendo à hierarquia descritiva habitual: primeiro livros e deuses, depois templos, a seguir sacerdotes, e, por fim, ritos e costumes. É neste contexto que surgem as referências a brâmanes, novamente referindo a sua obsessão com a pureza, mas desta vez com violência e ironia discursiva: "O maior pecado é ser tocado, os que presumem de nobres, dos que não o são, ainda que sejam raros em armas, letras e virtude. E o que mais é, nem, riqueza, destruidora de tantas linhagens muito ilustres, é ali poderosa para isto" ou "ficaram tão superiores que não só de tocar-se com outra gente, senão de se lhes chegar muito qualquer pessoa, ficam poluídos, que chamam empolados, e purificam-se." ${ }^{39}$ Prosseguindo na mesma linha, Faria e Sousa lembraria que essas prescrições se manifestavam, ainda, na recusa em

\footnotetext{
${ }^{38}$ Idem.

${ }^{39}$ Manuel Faria e Sousa, Ásia Portuguesa, vol. IV, pp. 250, 261.
} 
partilhar a mesa com pessoas de outra casta, em comer alimentos preparados por estas, em casar, e em variadas outras práticas de sociabilidade. ${ }^{40}$

\section{Tópicas da nobreza}

A cronologia destes discursos é semelhante à dos debates em torno à nobreza que se desenvolvem em Portugal, sobretudo a partir de meados do século XVI interdependentes, aliás, das dinâmicas de mobilidade social que se verificam nesse período - os quais podem ser divididos em dois subtipos: os debates em torno à origem natural ou política da nobreza (no contexto dos quais se pode situar a tratadística sobre a linhagem, a antiguidade da nobreza e a pureza de sangue, e a produção genealógica) e os debates em torno à nobreza das letras em contraponto com a nobreza de armas, que tinha evidentes conexões com o primeiro. ${ }^{41}$

Será que estes discursos sobre brâmanes e bramanismo interagiram com aqueles que, no reino, contemporaneamente, se estavam a desenvolver sobre a identidade nobiliárquica? Ou será que estamos perante discursos paralelos, com lugares de semelhança, mas entre os quais não é possível identificar trânsitos de significados?

No ensaio bibliográfico que João de Figueirôa-Rego fez na introdução à sua dissertação de doutoramento, A honra alheia por um fio. Os estatutos de limpeza de sangue nos espaços de expressão ibérica (sécs. XVI-XVIII), o espectro de influência que a limpeza de sangue adquiriu no mundo ibérico e seus impérios é amplamente demonstrado, ${ }^{42}$ nomeadamente ao nível de práticas institucionais que incorporaram os estatutos de limpeza de sangue como critério de aferição da qualidade dos candidatos a determinados ofícios, posições ou identidades. Os incontornáveis estudos de Fernanda Olival já tinham alertado para a maneira como os estatutos de limpeza de sangue, ao serem aplicados a várias instituições,

${ }^{40} \mathrm{Idem}$, pp. 258-260. Noutros lugares, porém, Faria e Sousa junta informação que parece contradizer esta (e relatos anteriores), segundo a qual os brâmanes do Malabar podiam sustentar várias mulheres, ainda que não brâmanes, o mesmo não podendo acontecer, contudo, com as mulheres brâmanes.

${ }^{41}$ Ver, a esse propósito a dissertação de doutoramento de Luís Fernando de Sá Fardilha, $A$ Nobreza das Letras: Os Sãs de Meneses e o Renascimento Português, Porto, FLUP, 2003 (manuscrito policopiado), a propósito do uso das letras como instrumento de prestígio nobiliárquico que complementava os feitos das armas.

${ }^{42}$ João de Figueirôa-Rêgo, "A honra alheia por um fio. Os estatutos de limpeza de sangue nos espaços de expressão ibérica (secs. XVI-XVIII)”, Braga, Universidade do Minho, dissertação manuscrita e policopiada, 2009. Agradeço ao autor, reconhecida, por me ter facultado o seu trabalho, ainda em vias de publicação. 
criavam regimes de exclusão de um vasto conjunto da população (e, por conseguinte, regimes de distinção para um outro conjunto populacional), cujos impedimentos podiam ser contornados por via de dispensas e dos requisitos necessários para as alcançar. ${ }^{43}$ Prosseguindo na mesma linha, Figueirôa-Rêgo mapeou as várias instituições (seculares e religiosas) e as múltiplas práticas (desde as inquirições, provanças e habilitações, até as genealogias, ou a tópica que foi sendo produzida no contexto das controvérsias surgidas em torno da aplicação dos estatutos de pureza de sangue) associadas à prova da limpeza de sangue e ao universo social que legitimava e que a legitimava. Por exemplo, Figueirôa mostrou como determinadas expressões podiam surgir nos processos de habilitação e nas provanças com o objectivo de impedir que determinado sujeito alcançasse uma dada distinção - caso dos vocábulos associados aos judeus e aos imaginários imundos que evocavam (cão, perro, cachorro).$^{44}$

Neste excelente estudo, o autor demonstrou a transversalidade da questão da limpeza de sangue a "vários contextos culturais de diferentes espaços geográficos". Na verdade, a "limpeza de sangue e contaminação constituíam de há muito pedras de toque no tecer de uma conflituosidade, latente ou abertamente declarada (consoante as épocas), em torno da cultura nobiliárquica e do fixar da honra e da qualidade social, em diferentes sociedades". No mundo ibérico da época moderna (e seus territórios imperiais) o seu impacto teria sido de tal ordem que, conclui, era praticamente impossível escapar à sua influência. ${ }^{45}$

Para além de terem providenciado o mapa das instituições, dos procedimentos associados à verificação da limpeza de sangue, e dos impactos sociais dos mesmos, estes trabalhos identificam, também, a agency dos sujeitos, e as estratégias que lhes permitiam contornar as imposições desenvolvidas pelos poderes. $\mathrm{Na}$ verdade, apesar do princípio estrutural que presidia aos estatutos de limpeza de sangue (o de vedar o acesso de boa parte da população às distinções mais apetecidas), as formas de contornar os impedimentos eram quase tantas quanto os impedimentos em si-mesmos. Ainda assim, e continuo a seguir Figueirôa-

\footnotetext{
${ }^{43}$ Fernanda Olival, As Ordens Militares e o Estado Moderno: Honra, Mercê e Venalidade em Portugal (1641-1789), Lisboa, Estar Editora, 2001, "Rigor e interesses: os estatutos de limpeza de sangue em Portugal”, Cadernos de Estudos Sefarditas, Lisboa, no 4, pp. 151-182.

${ }^{44}$ João de Figueirôa-Rêgo, op. cit., pp. 238 e ss.

${ }^{45} \mathrm{Idem}$, Introdução.
} 
Rêgo, seriam as próprias excepções a garantir a continuidade do sistema, já que "a entrada de outras gentes nas fileiras dos alegadamente bem-nascidos (leia-se dos puros) ao invés de desequilibrar a ordem social acabou por reforçá-la na sua essência”. Isto porque estes recém-chegados tendiam a ser muito estritos em relação à entrada de novos aspirantes. ${ }^{46}$

Apesar das inúmeras virtualidades dos excelentes estudos de Fernanda Olival e de João de Figueirôa-Rêgo, permanecem ainda por identificar muitos dos discursos que constituíram os universos de referência dos agentes envolvidos na concessão dos estatutos de limpeza de sangue e dos que ambicionavam obtê-los, sobretudo no que respeita a uma tratadística de cariz mais doutrinal, caso da tratadística nobiliárquica.

$\mathrm{Na}$ verdade, a bibliografia sobre a tratadística nobiliárquica produzida em contexto português nos séculos XVI e XVII, a partir da metrópole, é relativamente escassa, apesar de ter sido objecto de um número temático intitulado Nobrezas e Aristocracias da revista Penélope, de 1993. Nesse volume, António Manuel Hespanha abordou o tema no artigo "A Nobreza nos Tratados Jurídicos dos Séculos XVI a XVIII” e Nuno Gonçalo Monteiro em "Casa e Linhagem: o Vocabulário Aristocrático em Portugal nos séculos XVI e XVIII”. ${ }^{47}$ Nessa altura, Hespanha mostrou como os juristas se esforçaram por criar uma taxonomia bipolar - nobres vs. peões - a qual, segundo a sua argumentação de matriz aristotélica, decorria da própria ordem natural das coisas. Essa nobreza natural (a virtude (inata') traduzia-se depois em nobreza política, reconhecida pelo príncipe, ou reconhecida pela fama ou pela linhagem. I.e., havia como que uma 'fenomenologia' dessa nobreza natural, e o seu reconhecimento social pela graça régia era uma consequência quase inevitável do potencial inerente a cada sujeito que nascia nobre. Essa 'fenomenologia' expressava-se, em primeiro lugar, na geração, na linhagem (havendo controvérsia, porém, sobre se a transmissão era patrilinear e/ou matrilinear), esperando-se dos filhos de nobres, depois, que expressassem na vida cívica as virtudes dos seus pais e antepassados. ${ }^{48}$ Contudo, e como foi

\footnotetext{
${ }^{46}$ Idem, Conclusão.

${ }^{47}$ António Manuel Hespanha, "A Nobreza nos Tratados Jurídicos dos Séculos XVI a XVIII”, Penélope, no 12, 1993; Nuno Gonçalo Monteiro, "Casa e Linhagem: o Vocabulário Aristocrático em Portugal nos séculos XVI e XVIII”, Penélope, n 12, 1993.

${ }^{48}$ António Manuel Hespanha, op. cit.
} 
demonstrado por Nuno Monteiro, a partir da segunda metade do século XVII, o peso da linhagem no reconhecimento da nobreza tendeu a ser desvalorizada em relação à casa, muito embora continuasse a constituir um critério de distinção. ${ }^{49}$ Estas duas balizas cronológicas conformam, de certo modo, as características dos discursos sobre a nobreza no período sob estudo, e os mais recentes estudos de Jose Guillén Berrendero, que, nos últimos anos, se tem dedicado a comparar os mecanismos de honra e nobreza em Portugal e Castela a partir da tratadística nobiliárquica produzida em contexto ibérico, do que resultou a sua dissertação de doutoramento e alguns artigos, ${ }^{50}$ dão mais consistência ao quadro traçado por Hespanha e por Monteiro.

Dentro da tratadística nobiliárquica, Berrendero diferencia a tratadística genealógica $^{51}$ (aquilo que ele designa como uma verdadeira selva, composta por livros de linhagens e nobiliários, o que uma rápida sondagem pela "Colecção Pombalina”, na Biblioteca Nacional de Lisboa, permite confirmar) e a especificamente doutrinal, no contexto da qual a produção disponível é bastante mais modesta, como fez notar, aliás, António Caetano de Sousa na sua introdução à Historia Genealogica, e como uma pesquisa pela Biblioteca Lusitana de Barbosa Machado deixa entrever.

No século XVI destacam-se os livros quase contemporâneos de António Rodrigues (Tratado Geral da Nobreza) e de Jerónimo Osório (De nobilitate), os quais tiveram por objecto a origem e a natureza da nobreza, mas a ele pode ser acrescentado o atrás referido Tratado dos estados Eclesiásticos e Seculares de Diogo do Sá, o qual se configura, contudo, como um espelho. ${ }^{52}$

Jerónimo Osório propôs-se indagar do valor da nobreza, sua natureza e origem, de modo a que se pudesse perceber como alcançar a nobreza e "a distância

\footnotetext{
${ }^{49}$ Nuno Gonçalo Monteiro, op. cit., tema retomado e explorado mais intensivamente em O Crepúsculo dos Grandes, Lisboa, INCM, 1995.

${ }^{50}$ Jose Guillén Berrendero, Mecanismos de Honor y Nobreza en Castilla y Portugal, Madrid, 2009; "Honor and Service. Alvaro Ferreira de Vera and the idea of nobility in the Portugal of the Habsburgs", e-Journal of Portuguese History, vol. 7, n. 1, 2009.

${ }^{51}$ Ver a esse propósito, João de Figueirôa-Rêgo, Reflexos de um poder discreto, Lisboa, CHAM, 2008.

${ }^{52}$ O objectivo de Diogo do Sá, no Tratado dos Estados Eclesiásticos e Seculares, não era reflectir sobre as origens destes estados, mas sim, definir o perfil moral dos seus ocupantes, em diálogo directo com os perfis morais dos não cristãos, sobretudo judeus e hereges. Assim sendo, o seu tratado faz parte da literatura especular, orientadora de condutas, não abordando de maneira equivalente a questão da origem da nobreza e da sua transmissão.
} 
que se interpõe entre a verdadeira nobreza e o seu simulacro". Osório lembra que o vocábulo tinha um "uso assaz dilatado", pelo que no seu tratado o seu significado limitar-se-ia ao "lustre do sangue", ou seja, "os méritos mais grados, benéficos e acomodados à vida em sociedade". ${ }^{33}$

Ao contrário de Rodrigues, para quem a "nobreza natural" é a menos válida para aferir a nobreza de alguém, Osório começa por dizer que "a nobreza não se cifra na opinião, mas sim na natureza”, uma potência que supunha, contudo, a realização das virtudes que encerrava. Mais, este adjectivo podia aplicar-se a territórios e a famílias, do que resultava que o nascimento em "pátria ilustre" e de "geração nobre" tornava alguém potencialmente mais nobre do que aquele cuja proveniência não era aquela. ${ }^{54}$

Para sintetizar aquilo que ele próprio designa como a natureza e a origem da nobreza, o futuro bispo de Silves escreveria que a nobreza é "a índole natural que é inata nas almas mais excelentes, índole que, se estimada e confirmada pela antiguidade dos tempos alcança esplendor e senhorio de todo o género". ${ }^{55}$ Acrescentaria, ainda, que a antiguidade permitia "seleccionar" o que merecia ser preservado pela memória, para isso dando como exemplo os áticos, que não só proclamavam a sua antiguidade ("a razão que sejam estimadas por mais ilustres as castas que procederam durante dilatados anos"), como a ornavam com o facto de terem nascido em território grego, não admitindo "qualquer castiçamento com bárbaros ou forasteiros". ${ }^{66}$

Neste momento de síntese, Osório define a boa nobreza como aquela que era antiga, tinha linhagem pura e era nascida em território digno, três tópicos que iriam ser centrais nas posteriores discussões sobre a nobreza (ou a não nobreza) das populações nascidas no mundo ibérico e nos seus territórios imperiais. Contudo, o autor defende a historicidade da definição que ele próprio propõe, ao argumentar que era impossível que "este lustre de raça dure para sempre", razão pela qual havia muitas famílias de linhagens antigas que tinham desaparecido do conúbio dos nobres, enquanto novas famílias nobres podiam surgir, abrindo caminho para a incorporação de novos candidatos a nobre.

\footnotetext{
${ }^{53}$ Jerónimo Osório, Tratados da Nobreza Civil e Cristã. Lisboa, INCM, 1996, p. 89.

${ }^{54}$ Idem, p. 93.

${ }^{55}$ Idem, p. 107.

${ }^{56}$ Idem, pp. 105-106.
} 
O autor explica isto com recurso a uma outra teoria fundadora da nobreza a mesma de Rodrigues, mas aqui apresentada com maior sofisticação -, assente sobre as virtudes excepcionais de um sujeito que, depois, dava origem à linhagem nobre, sujeito esse que podia (e devia) ser reconhecido nobre pelo seu soberano. Não surpreende, pois, que Osório prossiga enunciando que virtudes eram essas (justiça, grandeza de ânimo, liberalidade, erudição), ${ }^{57}$ ao que contrapunha os vícios que conduziam à perda da nobreza natural (tirania, crime, iniquidade, cobardia, frouxidão, avareza) ${ }^{58}$

Dessa forma, e a partir de um mesmo princípio, Osório harmonizava duas modalidades de aquisição de nobreza que se situavam em dois pólos antagónicos: a linhagem e o mérito. Considerando a virtude de ânimo (a fonte do mérito) como origem última da nobreza, Osório hierarquiza e distingue aqueles cujos progenitores e antepassados o tinham já mostrado (ou seja, a continuidade linhagística da nobreza) e os que a tinham demonstrado recentemente.

Ao fazê-lo, Osório recorreu várias vezes à associação entre casta e nobreza, e entre casta e lustre do sangue, bem como à expressão "castiçamento", derivada da mesma raiz, a qual remetia para uma dinâmica de misceginação, por ele entendida negativamente. A associação entre estes vocábulos, ainda que não tivesse um papel central na teoria da nobreza desenvolvida por Osório dá conta de um template que iria ser transferido como quadro perceptivo dos grupos sociais que os portugueses encontraram na Índia, os quais, ao serem identificados como "casta" passavam a remeter para um determinado universo de identificação, distinção e exclusão, no qual a linhagem tinha um papel central. ${ }^{59}$

O Tratado da Nobreza Civil não pode ser lido sem ter em conta o Tratado da Nobreza Cristã, que lhe é complementar, permitindo a Osório, contudo, desenvolver melhor aquilo que entende por virtude de ânimo da qual procedia a nobreza, a "incontestável e constante fonte de virtude, que conserva com segurança a dignidade, não graças ao aparato, mas mercê da verdade”. Segundo Osório, numa formulação radical e semelhante à de Rodrigues, que iria, mais tarde, ser aproveitada pelas populações oriundas dos territórios imperiais entretanto

\footnotetext{
${ }^{57}$ Idem, pp. 112-123.

${ }^{58}$ Idem, pp. 124-128.

${ }^{59}$ Ver as considerações feitas a esse propósito por Rui Loureiro em Luís de Albuquerque et. al., O Confronto do Olhar. O Encontro dos povos na época das navegações, Lisboa, Caminho, 1991, pp. 160 e ss..
} 
cristianizadas, "não há variedade e diferença entre os povos nos quais brilha a nobreza divina". Todas as diferenças de partida - sangue, condição social, lugar de nascimento - se transformavam "depois que foram limpos pelas águas lustrais" num "mesmo vínculo de agnação e parentesco", numa "única raça: para ela é um só culto, uma só a linhagem, um só o tronco donde procede". ${ }^{60}$ Esse tronco comum era a linhagem cristã, a qual remontava "aos primórdios do Universo" e cujos verdadeiros herdeiros não eram os judeus, mas os cristãos genuínos do mundo inteiro. Sublinhe-se as intertextualidades que se verificam, em Osório, entre a tópica sobre a linhagem e sua antiguidade e a antiguidade da pertença cristã, as quais permitem-lhe recompor o discurso e exprimir-se abertamente a favor da antiguidade da linhagem cristã.

Importa referir, aqui, as reflexões mais modestas de António Rodrigues. Procurando responder à dúvida "se os convertidos a nossa fee que segumdo sua ley ou seita eram nobres de xpãaos retem a nobreza”, o autor dedica algumas páginas ao tema, argumentando que " como quer que o judeu ou mouro segdo sua lley posa virtuosamente viver as vertudes aos bautizados podem tamto valler que por Ellas muy asinha ganhar a nobreza theologal". Na verdade, Rodrigues faz uma defesa acérrima da nobreza antiga dos judeus, e a sua nobreza teologal original, por serem profetas de cuja linhagem tinha saído Cristo. Segundo Rodrigues, a nobreza dos judeus tinha-se perdido porque estes tinham prevaricado, mas que regressando ao grémio cristão, recuperavam as suas velhas virtudes. Conclui, aliás, dizendo que "mylhões de judeus sam comvertidos despois da vimda de noso sñor ate oye", insinuando que havia muitos descendentes de judeus que não o sabiam por a memória ser já perdida. ${ }^{61}$

No século XVII, é o tratado de Álvaro Ferreira de Vera, Origem da nobreza politica, blasoes de armas, appellidos, cargos \& titullos nobres, publicado em 1631. Como refere Berrendero, tal como Rodrigues e Osório, a primeira fonte de Vera é Aristóteles, tanto na Política como na Ética, combinado, depois, com historiadores e outros tratadistas sobre a nobreza. Mas para Vera era já certo que a nobreza era atribuída pelo Príncipe, como remuneração dos serviços (a virtude), apesar de a linhagem e a antiguidade terem valor enquanto critério de nobreza: ${ }^{62}$ "não

\footnotetext{
${ }^{60}$ Jerónimo Osório, op. cit., p. 181.

${ }^{61}$ António Rodrigues, Tratado Geral da Nobreza Porto, Biblioteca Pública Municipal, 1931, pp. 50-53.

${ }^{62}$ Jose Guillén Berrendero, op. cit.
} 
porque a linhagem seja causa eficiente, como o é a virtude remunerada pelo Príncipe, se não porque já o Príncipe enobreceu aquela geração em cabeça do primeiro e lhe deu a eles a mesma nobreza. E assim estes, que são nobres por linhagem, não têm mais privilégios que o primeiro daquela sua linhagem. Porém, tem uma estima maior por se haver aquele seu princípio dilatado e continuado nos descendentes com a propagação natural e antiguidade no tempo. De tal maneira que quanto mais se dilatar e mais antiguidade tiver, tanto de mais estima irão cobrando os descendentes deste primeiro autor da tal nobreza". ${ }^{63}$

Contudo, Vera insiste no facto de ter havido desde sempre uma opinio favorável à transmissão da nobreza pelo sangue (Aristóteles, Quintiliano, Piccolomini) e uma outra que privilegiava as "assinaladas façanhas" (Boécio, Plutarco, Petrarca). Citando frei Amador de Arrais, Vera diz "lastimosa coisa é não ter o homem mais nobreza própria que quanta deriva de seus avós", ${ }^{64}$ dedicando, inclusive, um capítulo aos que "degeneraram da nobreza que herdaram", ao qual contrapõe um outro relativo aos que eram "baixos e humildes", alcançando "grandes honras e dignidades", "por seus merecimentos". ${ }^{65}$

Ao longo do seu tratado, Vera recorre aos autores e exemplos clássicos para sustentar a sua argumentação, muito raramente evocando casos asiáticos. Contudo, no final do seu tratado, ao fazer uma síntese das causas da nobreza (virtude, valor, letras) refere-se à "gente escolhida da casta real e santa", ao invocar os que eram nobres por virtude, i.e., os sacerdotes, religiosos e pessoas consagradas a Deus. Além disso, e apesar de insistir na origem política da nobreza, acaba por aceitar, à maneira de Jerónimo Osório, que aqueles que "são nobres por suas linhagens e por si, são mais qualificados e estimados do que os outros a que se concedeu a nobreza. A razão é porque aquela virtude dos primeiros está mais aumentada e quase perpétua em seus descendentes" ${ }^{66}$

\section{Trânsitos ou incomunicabilidade entre duas tópicas de distinção?}

Estes primeiros exemplos não permitem afirmar que houve transacções directas entre a tópica bramânica - tal como ela surgia declinada nas representações

\footnotetext{
${ }^{63}$ Álvaro Ferreira de Vera, Origem da Nobreza Politica, Lisboa, Livro Aberto, 2005, p. 24.

${ }^{64}$ Idem, pp. 51, 53.

${ }^{65}$ Idem, caps. VIII e IX.

${ }^{66}$ Idem, pp. 63-64.
} 
que circulavam no espaço português - e a tópica nobiliárquica que emerge na principal tratadística sobre a nobreza. De facto, se não considerarmos as escassas referências ao vocábulo 'casta', de origem portuguesa, mas que, dado o seu intensivo uso em contexto asiático, rapidamente os seus conteúdos se indianizaram, poucos mais são os vestígios que aqui se podem encontrar.

Esta ausência pode indiciar, à partida, duas coisas, não necessariamente exclusivas uma da outra, mas provavelmente articuladas entre si.

Por um lado, pode indiciar que estes se tratavam, do ponto de vista das tradições escritas, de universos de escrita paralelos que raramente se tocavam. $\mathrm{Ou}$ seja, provavelmente o autor de um tratado nobiliárquico não recorria à literatura de viagens, ou à tratadística sobre o 'outro', no momento de pesquisa de exempla úteis à sua argumentação, por, nos séculos XVI e XVII, esta literatura não fazer parte do corpus normalmente utilizado pelos portugueses para discutir estas questões. Havia leituras típicas a fazer, e eram essas as que alimentavam a escrita nobiliárquica. A não ser que o autor tivesse, ele próprio, um interesse directo no conhecimento das realidades sociais imperiais. Quer isto dizer que a escrita mainstream, metropolitana, era tendencialmente insensível às experiências sociais do império e ao modo como estas alimentavam a escrita e, inclusive, novas tópicas (e modelos?) de distinção? Talvez.

É igualmente possível, por outro lado, que as escritas relativas às sociedades do império, ou produzidas a partir do império, tivessem, na imaginação metropolitana, um estatuto menor do que aquelas que eram produzidas no centro, não servindo, por isso mesmo, para alimentar a enciclopédia referencial, a não ser quando era necessário exoticizar o próprio discurso.

Talvez não surpreenda, por isso mesmo, que em vez de haver impacto do bramanismo nas tópicas de distinção produzidas no reino se verifique - em correlação com as assimetrias do poder político - ao contrário. Até finais do século XVII seria a tratadística nobiliárquica de origem portuguesa a ter impacto sobre o bramanismo local, e não o inverso.

Ao mesmo tempo que os portugueses (ou europeus) que viajavam até à Índia ou que aí se estabeleceram, registravam, tematizavam, e discorriam sobre os brâmanes a partir de livros escritos por estes, ou por antigos teólogos seus, nas versões que circulavam nos lugares por onde passavam, a partir de versões por eles providenciadas, e a partir da própria experiência, brâmanes convertidos 
ao Cristianismo desenvolveram uma escrita de contornos identitários, na qual expressaram auto-representações em diálogo directo com a tratadística nobiliárquica de origem portuguesa.

Esta escrita adquiriu, pelo menos, duas dimensões - uma assertivamente identitária (e a Aureola dos Indios e a Cronologia da Congregação do Oratório enquadra-se neste tipo), e uma outra, do tipo polémico, caso da disputa encabeçada por João da Cunha Jaques, o qual assumindo o seu vínculo à casta charodo, segundo ele descendente dos míticos kshatryas, procurou desmontar, no tratado David contra o Golias do Bramanismo, os argumentos desenvolvidos pelos brâmanes de Goa. ${ }^{67}$

O título deste tratado valeria, por si-próprio, uma pausa, já que se trata de uma bela síntese desse palco da escrita onde diversas tópicas se podiam encontrar; servindo a tópica cristã, neste caso, como uma poderosa arma que podia ser brandida contra a tópica bramânica já cristianizada.

O tratado do padre Jaques faz parte de um conjunto de textos que foram produzidos por indianos convertidos ao Cristianismo, a partir da segunda metade do século XVII, possivelmente na sequência do impacto que a acção de Mateus de Castro, bispo de Crisópolis, teve nos equilíbrios sociais e políticos de Goa. De facto, o Espelho de Bramenes escrito por este e divulgado a partir de 1653 defendia a ideia de que os brâmanes de Goa eram maltratados pelos portugueses, o que era inadmissível, sendo que muitos daqueles eram filhos ou descendentes de regateiras e de peixeiras. ${ }^{68}$

O tom violento, controverso, de Mateus de Castro, e até mesmo a memória do seu tratado, iriam ser mitigados nos textos subsequentes (por exemplo, na Cronologia da Congregação do Oratório de Goa do padre Sebastião do Rego, a experiência de Castro nem sequer é referida), e a luta que aí se vislumbrava (entre colonizadores e colonizados) estender-se-ia aos próprios colonizados, os quais

\footnotetext{
${ }^{67}$ Ver, a propósito das disputas que se discutem em seguida, o capítulo 7 de Ângela Barreto Xavier, $A$ invenção de Goa, op. cit., e "David contra Golias...”, op. cit., e ainda Ines Županov, "Conversion historiography in South Asia - counter space for alternative histories in 18th century Goa", Medieval History Journal, Theme Issue Conversions, ed. Monika Juneja e Kim Siebenhüner, 12, 2, 2009, pp. 303-325.

${ }^{68}$ Sobre Mateus de Castro, ver Giuseppe Sorge, Matteo de Castro (1594-1677) profilo di una figura emblematica del conflitto giurisdizionale tra Goa e Roma nel secolo 17, Bologna, CLUEB, 1986; Ângela Barreto Xavier, A Invenção de Goa, op. cit., cap. 7; e Patrícia Souza Faria, "Mateus de Castro: um bispo 'brâmane' em busca da promoção social no império asiático português (século XVII)", Revista Eletrónica de História do Brasil, vol. 09, n. 2, Jul-Dez 2007, pp. 31-43.
} 
acabariam por disputar, entre si, e com o recurso à tópica cristã, a maior nobreza (e pureza?) da sua identidade.

É isso que opõe António João Frias, da aldeia de Talaulim, filho de Pascoal João Frias, o qual, alcançara já, depois de muitas outras benesses, o foro de cavaleiro fidalgo em $1690,{ }^{69}$ a Leonardo Paes, igualmente bem sucedido no seu cursus honorum. No seu Promptuario de Deffinicoes Indicas, na parte designada " $\mathrm{Da}$ gente da India", discorre sobre as "castas", afirmando a antiguidade da linhagem charodo (descendente de Indo, um dos filhos de Noe), em contraponto com os brâmanes, sobre quem se recusa a escrever, argumentando que estes eram estrangeiros à Índia. Mas Paes dedica uma das partes do livro a desmontar a argumentação bramânica, nomeadamente as ideias de que "as nobrezas das famílias se medem pelas antiguidades", e de que eles eram mais antigos. Nessa mesma parte, Paes pretende desmontar a ideia veiculada pelos brâmanes de que só eles tinham acesso ao colégio da Propaganda Fide, ao tribunal do Santo Oficio, à Secretaria e Chancelaria do Estado da India, ao convento de Santa Mónica, um elenco que providencia uma primeira etnografia das exclusões no Estado da Índia que tinham por base o "sangue indiano" que não era de origem brâmane. ${ }^{70}$

Em suma, as "representações do bramanismo" (parte de uma outra formação discursiva - o Orientalismo) podem ser entendidas como um "discurso transverso", que se "encontrou" com os discursos de linhagem e pureza produzidos no contexto metropolitano e imperial da coroa de Portugal, possivelmente fazendo parte, ambos, da genealogia do racismo. A confluência de ambos os discursos em determinados textos produzidos por brâmanes cristianizados de Goa reflectiu uma outra etapa deste processo, e a sua corporeização em novas modalidades discursivas que tinham como objecto, agora, outros corpos (já não apenas o corpo do cristão-novo, já não apenas o corpo do brâmane, mas sim o corpo do brâmane convertido).

A estes processos não terão sido alheias às dinâmicas identitárias que se desenvolviam na Índia nesse mesmo período. Esta pertença regional dos discursos produzidos pelos indianos convertidos ao Cristianismo de Goa parece-me inquestionável, assim como as pontes que se podem estabelecer entre os formatos

\footnotetext{
${ }^{69}$ João de Figueirôa-Rêgo, "A honra alheia por um fio", op. cit., 1.2. "O Império português na Índia: brâmanes e chardós".

${ }^{70}$ Leonardo Paes, Promptuario de Diffinições Indicas, Lisboa, 1713, tratado III, caps. 3 e 4, tratado IV.
} 
por eles escolhidos e a escrita que circulava nas regiões vizinhas. Efectivamente, a extensão desta problemática aos espaços imperiais obriga a dar uma maior atenção a discursos paralelos que se podiam estar a desenvolver nesses lugares independentemente da relação colonial (a pureza e a genealogia, por exemplo, tiveram um papel central na definição da identidade bramânica, nesta mesma altura, à semelhança do que acontecia, aliás, no mundo judaico). De facto, o puzzle que aqui pretendo construir só adquire sentido se estiver em diálogo com esses outros puzzles, nomeadamente, as histórias concretas por detrás de tais experiências discursivas, as quais podem ser iluminadas pelos excelentes trabalhos de Sheldon Pollock, Sanjay Subrahmanyam, David Shulman, Velcheru Narayna Rao, Sumit Guha, Kapil Raj, ou Rosalind O’Hanlon e Christopher Minkowski, sobre os processos intelectuais e políticos que caracterizaram a Índia 'pré-britânica.' ${ }^{71}$

Por fim, e com o objectivo de complexificar ainda mais estas já complicadas equações (inserindo o tema da imitação colonial num contexto inter-imperial), interessa-me, e tendo presentes os magníficos estudos de Thomas Trautmann e de Tony Ballantyne, de certo modo ainda na sequência do Imagining India de Ronald Inden, colocar ainda outras questões. ${ }^{72}$ Por um lado, e à semelhança do que fizeram estes autores, gostaria de saber se brâmanes e bramanismo ocuparam um lugar homólogo no contexto imperial português aos que os arianos e o arianismo terão ocupado, segundo estes autores, no mundo britânico, "aproximando" colo-

\footnotetext{
${ }^{71}$ Sheldon Pollock, ed., Literary Cultures in History:Reconstructions from South Asia, Berkeley, U. of California Press, 2003; "Literary Culture and Manuscript Culture in Precolonial India", in Simon Eliot, Andrew Nash, Ian Willison, eds., History of the Book and Literary Cultures, London: British Library, 2006, pp. 77-94; Sumit Guha, "Speaking Historically: The changing voices of historical narration in Western India, 1400-1900", American Historical Review, 109, 4 (October 2004 ), 10841103; "Serving the barbarian to preserve the dharma: the ideology and training of a clerical elite in peninsular India, c. 1300-1800", Indian Economic and Social History Review, October/December 2010, vol. 47 no. 4, pp. 497-525; Sanjay Subrahmanyam, Penumbral Visions: making polities in early modern South India, University of Michigan Press, 2001; Richard Maxwell Eaton, A Social History of the Deccan: 1300-1761: eight Indian lives, Gordon Johnson, gen. ed., New Cambridge History of India, vol. 8, Cambridge, CUP, 2005, pp. 184 e ss.; Rosalind O'Hanlon e Christopher Minkowski, "What makes people who they are? Pandit networks and the problem of livelihoods in early-modern India”, Indian Economic Social History Review, vol. 45, no. 3, September 2008, pp. 381-416.

${ }^{72}$ Thomas Trautmann, Aryans and British India, Berkeley-Los Angeles-London, University of California Press, 1997; Tony Ballantyne, Orientalism and Race, Basingtoke, Palgrave MacMillan, 2005; Ronald Inden, Imagining India, Cambridge, Blackwell, 1990. Falar de pureza ritual e de bramanismo evoca, necessariamente, Louis Dumont e o seu Homo hierarchicus (1968), mas não é este o template de leitura da cultura e da sociedade indiana que aqui se adopta.
} 
nizadores (alguns colonizadores) e colonizados (alguns colonizados), e ajudando a constituir a figura do colonizado. Por outro, gostava de entender de que forma é que estas experiências em contexto imperial português interagiram com (fizeram parte de, foram repetidas ou imitadas por) as experiências imperiais britânicas na Índia, ${ }^{73}$ e se sim, de entender por que é que elas desapareceram do horizonte da historiografia britânica. Em que medida é que os impactos daquilo que Trautmann (para quem, em todo o caso, o orientalismo já era quase e apenas, o francês e o holandês dos séculos XVII e XVIII) designou de "titanic shift in authority", a propósito da emergência da Asiatic Society, e da revista Asiatick researches, como os lugares legítimos de produção orientalista, ${ }^{74}$ ajudam a explicar o apagamento historiográfico quase completo das experiências ocorridas em contexto imperial português, na Índia, ou a sua mera deslocação para o território da "lenda negra"?

Se for possível estabelecer conexões entre discursos identitários, hierárquicos, e paralelos, que operavam nestas várias ordens sociais, deixa de surpreender que no Estado da Índia, o ideal da mestiçagem física, até pela sua proximidade à ideia de contaminação, tenha tido uma vida particularmente difícil, já que surgia como o reverso das dinâmicas que sublinhavam o ideal de pureza do sangue, que eram partilháveis tanto pelas elites portuguesas metropolitanas, quanto por boa parte das elites de origem indiana. E entende-se melhor, também, por que é que, depois de um início problemático - dadas as críticas violentas que lhes foram feitas por Francisco Xavier, em meados do século XVI - estes grupos adquiriram um inegável prestígio no contexto imperial português, ocupando com frequência o lugar de intermediários.

Apesar de este não ser o momento para enveredar por este caminho nem pelos importantes debates surgidos a esse propósito, a verdade é que os conhecimentos sobre a Índia que emergiram no horizonte imperial português - e a historiografia que os elege como objecto - têm de dialogar, imprescindivelmente, com estes múltiplos processos históricos e suas historiografias, de modo a não enquistar esta problemática ao mundo ibérico quando os seus contornos têm, talvez, uma escala bem maior. As escalas de leitura dos processos históricos nos quais

\footnotetext{
${ }^{73}$ Em Mimesis and Empire, The New World, Islam and European Identities (Cambridge, CUP, 2001), Barbara Fuchs propôs fazer um exercício sob alguns aspectos semelhantes no que respeita às articulações entre Inglaterra, Espanha e Otomanos na época moderna, em contexto mediterrânico e atlântico.
}

${ }^{74}$ Thomas Trautmann, Aryans and British India, op. cit., p. 30. 
os portugueses estiveram envolvidos são múltiplas e de vária natureza geográfica, histórica, historiográfica, e mesmo um tema aparentemente circunscrito, como o que aqui me propus tratar, pode facilmente tornar-se numa pesquisa múltipla e complexa, como me parece ter ficado claro quer das observações introdutórias quanto destes últimos e ainda que não conclusivos parágrafos. 